ARTIGO

do https://doi.org/10.22481/praxisedu.v16i40.6580

\title{
ESTADO DO CONHECIMENTO: A DIALOGICIDADE ENTRE A EDUCAÇÃO IN- CLUSIVA E A EDUCAÇÃO DE JOVENS E ADULTOS
}

\author{
STATE OF KNOWLEDGE: THE DIALOGICITY BETWEEN INCLUSIVE EDUCATION \\ AND THE EDUCATION OF YOUTH AND ADULTS
}

\begin{abstract}
ESTADO DEL CONOCIMIENTO: LA DIALOGICIDAD ENTRE LA EDUCACIÓN INCLUSIVA Y LA EDUCACIÓN DE JÓVENES Y ADULTOS
\end{abstract}

\author{
Keren Talita Silva Miron \\ Instituto Federal Catarinense - Brasil \\ Chris Royes Schardosim
}

Instituto Federal Catarinense - Brasil

\begin{abstract}
Resumo: Este trabalho tem como objetivo verificar e analisar o quantitativo e o que revelam os trabalhos publicados na biblioteca virtual nacional da Associação Nacional de Pós-Graduação e Pesquisa em Educação (ANPEd), que dialogassem com a Educação Inclusiva dentro Educação de Jovens e Adultos (EJA), em um recorte temporal do ano de 2005 a 2017. A compreensão dos dados fundamenta-se nos pressupostos da abordagem qualitativa, de caráter descritivo-reflexiva (BARDIN, 2011). Do ponto de vista técnico-metodológico, a base foi análise bibliográfica (RIZOLA; FANTIN, 2016), na qual utilizamos o método de pesquisa Estado do Conhecimento (MOROSINI, 2015). Dessa forma, buscamos os artigos que trouxessem o diálogo entre Educação Inclusiva e EJA para perceber o que os trabalhos revelavam sobre os temas, quais as ligações feitas e como eles poderiam nos ajudar a pensar a relação dialógica da temática investigada. Os resultados da pesquisa evidenciam que, apesar da relevância dos artigos analisados, ainda há muitas lacunas dentro da reflexão dessa temática: estudos que dialoguem sobre a formação de professores para atuarem na perspectiva inclusiva na EJA; qual a melhor maneira de estruturar a modalidade em uma perspectiva inclusiva; a interrelação entre os participantes; bem como os aspectos e desdobramentos curriculares dentro dessa perspectiva.
\end{abstract}

Palavras-chave: Estado do conhecimento. Educação inclusiva. Educação de jovens e adultos.

\begin{abstract}
This work aims at verifying and analyzing the quantity of works published in the national virtual library of the Associação Nacional de Pós-Graduação e Pesquisa em Educação (ANPEd) and what such works reveal through the dialogue they attempt to establish with Inclusive Education within Youth and Adult Education (EJA), from 2005 to 2017. The data is based on the assumptions of the qualitative approach, in a descriptive-reflexive terms (BARDIN, 2011). From a technical-methodological point of view, the present research was based on bibliographic analysis (RIZOLA; FANTIN, 2016), in which we used notions of the State of Knowledge research method (MOROSINI, 2015). Thus, articles that brought the dialogue between Inclusive Education and EJA were used in order to understand
\end{abstract}


what the works revealed about the themes, what connections were made and how such articles could help us to think about the dialogical relationship of the theme investigated. The results of the research indicate that, despite the relevance of the articles analyzed, there are still various gaps in the development of this theme: studies that discuss the training of teachers to operate in an inclusive perspective in EJA; what is the best way to structure the sport in an inclusive perspective; the interrelationship between the participants; as well as the curricular aspects and developments within this perspective.

Keywords: State of Knowledge. Inclusive education. Youth and adult education.

Resumen: Este trabajo tiene como objetivo verificar y analizar lo cuantitativo y lo que revelan los trabajos publicados en la biblioteca virtual de la Associação Nacional de Pós-Graduação e Pesquisa em Educação (ANPEd), que dialoguen con la Educación Inclusiva dentro de la Educación de Jóvenes y Adultos (EJA), en un período de tiempo desde el año 2005 al 2017. La comprensión de los datos se basa en los supuestos del enfoque cualitativo, de carácter descriptivo-reflexivo (BARDIN, 2011). Desde un punto de vista técnico-metodológico, la base fue el análisis bibliográfico (RIZOLA; FANTIN, 2016), en el que utilizamos el método de investigación del Estado del Conocimiento (MOROSINI, 2015). De esa manera, buscamos artículos que trajeron el diálogo entre Educación Inclusiva y EJA para percibir lo que revelaron las obras sobre los temas, qué conexiones se hicieron y cómo podrían ayudarnos a pensar sobre la relación dialógica del tema investigado. Los resultados de la investigación muestran que, a pesar de la relevancia de los artículos analizados, todavía hay muchas lagunas en la reflexión de este tema: estudios que dialoguen sobre la capacitación de profesores para actuaren en la perspectiva inclusiva en EJA; cual la mejor manera de estructurar la modalidad en una perspectiva inclusiva; la relación entre los participantes; así como los aspectos y desdoblamientos curriculares desde esa perspectiva.

Palabras clave: Estado del conocimiento. Educación inclusiva. Educación de jóvenes y adultos.

\section{Iniciando o diálogo}

O enfoque deste texto é analisar e discutir o quantitativo e os dados de trabalhos que dialoguem com a temática de Educação Inclusiva dentro da Educação de Jovens e Adultos (EJA). Ocorreu por interesse e estudos realizados pelas autoras deste artigo ao longo da graduação da mestranda e nas pesquisas no Mestrado Acadêmico em Educação no Instituto Federal Catarinense.

Este trabalho é uma análise bibliográfica a partir de Rizola e Fantin (2016) e Morosini (2015), no qual utilizamos o método de pesquisa estado do conhecimento, com o objetivo de verificar e analisar o quantitativo e o que revelam os trabalhos publicados na biblioteca virtual nacional da Associação Nacional de Pós-Graduação e Pesquisa em Educação (ANPEd), que dialogassem a Educação Inclusiva dentro da EJA, em um recorte temporal do ano de 2005 a 2017.

Ainda, destacamos que os eixos em temáticas objetivados têm suas relevâncias a partir da compreensão de que a inclusão dentro da escola não se trata apenas de uma opção, e sim um direito constitucional garantido por Lei. Posto isso, compreendemos que os jovens e adultos 
com deficiência não ficam de fora quando a Constituição Federal de 1988, no art. 205, declara que a Educação é direito de todos. E entender como essa inclusão tem sido abordada dentro do campo de pesquisas acadêmicas torna-se relevante à medida que permiti averiguar como esses sujeitos estão sendo incluídos no âmbito escolar.

Portanto, para abordarmos a temática aqui apresentada, além da introdução e das considerações finais, este trabalho contém dois tópicos centrais: o primeiro se reporta ao percurso metodológico para o desenvolvimento deste trabalho; o segundo apresenta os resultados da investigação.

\section{Metodologia}

Para a realização deste trabalho, utilizamos o método estado do conhecimento. Entendemos que esse método é a sistematização de trabalhos sobre uma temática específica e em determinada área do conhecimento, por meio de uma busca em bancos de dados nacionais e internacionais de periódicos, dissertações, teses ou livros. Ainda, destacamos que esse método, ao fazer um levantamento sobre as publicações de determinado tema específico, precisa estabelecer um recorte temporal que considere significativo para as análises e reflexões.

Corroborando com nosso entendimento, Morosini (2015, p. 102) conceituou que o "estado de conhecimento é identificação, registro, categorização que levem à reflexão e síntese sobre a produção científica de uma determinada área, em um determinado espaço de tempo [...]”. Ainda para a autora, esse método visa o desafio de mapear, catalogar e discutir; além de possibilitar análises e avaliação da produção em áreas de interesse, de maneira a mostrar que aspectos e dimensões de estudos têm sido destacados e privilegiados em épocas e lugares distintos.

Morosini e Fernandes (2014, p. 158), apontam os objetivos do estado do conhecimento: "fornece um mapeamento das ideias já existentes, dando-nos segurança sobre fontes de estudo, apontando subtemas passíveis de maior exploração ou, até mesmo, fazendo-nos compreender silêncios significativos a respeito do tema de estudo". Ainda, Morosini (2015, p. 110), ao trazer mais categoricamente esses objetivos apresenta-os como

Conhecer, sistematizar e avaliar a produção científica da área da Educação na contemporaneidade; elaborar produção textual, apoiada em princípios de estado de conhecimento sobre a temática da tese ou dissertação; subsidiar a construção da dissertação e/ou tese em educação; cultivar habitus científico, visando à prática de pesquisa articulada à realidade; e compreender a produção científica na perspectiva do seu campo. 
Nessa perspectiva, entendemos que esse método representa importantes contribuições na constituição do campo teórico de uma área do conhecimento, seja pela identificação das colaborações significativas na construção da teoria e prática pedagógica, ou por buscar sinalizar as restrições e desafios acerca do campo em que se move a pesquisa e possibilitar alternativas para soluções de problemas.

No que se refere à análise de dados, seguimos os indicadores propostos por Bardin (2011), a qual mostra que a análise de conteúdo prevê três polos cronológicos fundamentais: pré-análise, exploração do material e tratamento dos resultados (a inferência e a interpretação). Todavia, antes de adentramos nos desdobramentos deste trabalho e da análise dos dados, ressaltamos que o nosso percurso metodológico ganhou forma no decurso de sua realização e para melhor apresentarmos, o dividimos em três fases: a primeira fase trata da coleta de dados; a segunda fase, a pré-análise, que foi dividida em duas etapas, a geral e a específica; e por fim, a terceira fase, que foi o tratamento e análise dos resultados que originou a última seção desta pesquisa, todas serão explicitadas na continuação.

\subsection{Primeira fase: coleta de dados}

A primeira fase deste trabalho foi a coleta de dados. Executada dentro da biblioteca virtual no site da ANPEd, na qual procuramos coletar todos os artigos publicados nos eventos nacionais nos Grupos de Trabalhos (GTs), especificamente o GT 15 e o GT 18. Esses GTs foram escolhidos mediante o critério de serem grupos de trabalhos com publicações de artigos que trazem os eixos temáticos discutidos nesse trabalho. O GT 15 referente à Educação Especial, e GT 18 referente à EJA.

Já ao que se refere ao período temporal para o desenvolvimento dessa investigação, optamos pelo recorte dos anos de 2005 a 2017. Isso porque consideramos um período bastante significativo de avanços e retrocessos nos aspectos legais, mudanças em questões políticas, sociais e culturais dentro do campo da educação. Assim, consideramos de suma importância compreender o que esses trabalhos revelam diante dessas transformações.

Ainda destacamos que a escolha pelo campo de análise no arsenal da biblioteca virtual das reuniões da ANPEd justifica-se por compreendermos a sua grande representatividade na área da Educação e pela sua significativa trajetória no meio das pesquisas acadêmicas. Além disso, vemos como um espaço de estudos e pesquisas que permitem a discussão de assuntos 
pertinentes e fundamentais para rupturas de paradigmas, apesar dos territórios de análises distintos, mas que se aproximam em um pensar epistemológico. Posto isto, enfatizamos, que embora nosso objetivo principal pautava-se na análise dos artigos que trouxessem a dialogicidade da Educação Inclusiva dentro da EJA, um dos nossos objetivos específicos era a construção de um catálogo, que possibilitasse verificar de forma geral, os temas abordados dentro do banco de dados dos GTs pesquisados.

Assim, nesta primeira fase, não houve a preocupação de retirarmos apenas os trabalhos que dialogassem com os eixos temáticos objetivados, mas todas as publicações encontradas. Essa escolha foi feita por acreditarmos que a visão desses dados poderia auxiliar outras pesquisas na área, além de possibilitar uma maior clareza para o desenvolvimento e a discussão das nossas ideias dentro deste trabalho.

\subsection{Segunda fase: pré-análise}

Dando sequência, a segunda fase foi a da pré-análise, apresentada por Bardin (2011) como a fase da organização e sistematização das ideias iniciais. Nessa fase, estabelecemos um esquema de trabalho efetivo e preciso, divididos em duas etapas. A primeira etapa foi denominada de "etapa geral" e a segunda, "etapa específica".

$\mathrm{Na}$ etapa geral, as nossas análises e investigações foram feitas em todos os artigos encontrados, de maneira que procuramos realizar uma análise quantitativa dos trabalhos. Uma vez que nossa proposição nessa etapa foi conhecer os trabalhos, os temas e os anos que mais tiveram pesquisas publicadas. Ao que se refere aos critérios de categorização dessa etapa foram definidos em: classificação e separação das publicações de acordo com os temas centrais.

Já na etapa específica, procuramos de forma cuidadosa explorar os artigos que trouxessem o diálogo entre Educação Inclusiva e EJA. De modo a perceber o que os trabalhos revelavam sobre os temas, quais as ligações feitas e como eles poderiam nos ajudar a pensar a relação dialógica da temática investigada, mediante a realização de leituras mais profundas e fichamentos. Para isso definimos como critérios de análise: objetivo da pesquisa, contextualização, metodologia utilizada, pontos de destaque e pontos de limitações.

\subsubsection{Etapa Geral}

Para facilitar a nossa compreensão e ajudar a analisar os artigos, na etapa geral organizamos um quadro de apreciação que respondesse aos seguintes critérios de investigação: título, autores, tipo de publicação e ano de publicação, como está exemplificado na figura 1 abaixo. A 
partir desses critérios, começamos a organizar uma planilha com os artigos encontrados em cada GT.

Figura 1: Critérios para catalogação dos dados

\begin{tabular}{|c|c|c|c|}
\hline \multicolumn{4}{|c|}{$\begin{array}{l}\text { TRABALHOS } 2005 \text { A } 2017 \\
\text { GRUPO 15: EDUCAÇÃO ESPECIAL }\end{array}$} \\
\hline TÍTULO & AUTORES & $\begin{array}{c}\text { TIPO DE } \\
\text { PUBLICAÇÃO }\end{array}$ & ANO \\
\hline $\begin{array}{l}\text { 1. Universidade, Educação Especial E } \\
\text { Formação De Professores }\end{array}$ & $\begin{array}{l}\text { Almeida, Carina } \\
\text { Elisabeth Maciel De.- } \\
\text { Ucdb (Capes/Prosup) }\end{array}$ & Trabalho & 2005 \\
\hline $\begin{array}{l}\text { 2. Da Educação Especial Ȧ Educação } \\
\text { Inclusiva? A Proposta De "Inclusão } \\
\text { Escolar" Da Rede Estadual De Goiás No }\end{array}$ & $\begin{array}{l}\text { Almeida, Dulce } \\
\text { Barros De - Ufg }\end{array}$ & Trabalho & 2005 \\
\hline
\end{tabular}

Fonte: Elaborado pelas autoras

Após essas definições, foram feitas leituras flutuantes, definida por Bardin (2011) como uma atividade que tem o objetivo de estabelecer o contato com os documentos a analisar e conhecer o texto, de forma a perceber as impressões e orientações que nele estão presentes. Ainda a autora destaca que "esta fase é chamada de leitura «flutuante» por analogia com a atitude do psicanalista". (BARDIN, 2011, p. 96). Assim, pudemos estabelecer um contato maior com os artigos coletados e a partir disso, elaboramos indicadores de orientação que nos ajudaram na organização e interpretação do material.

Ainda, dentro dessa etapa, no segundo momento, após verificarmos em cada trabalho os critérios de investigação, passamos a definir temas centrais, a fim de separarmos os artigos em grupos. Então, estabelecemos que as publicações que dialogassem sobre o mesmo assunto seriam organizadas em uma mesma planilha. Segue abaixo, os quadros elaborados com os temas centrais dos GTs. Quadro 1, refere-se ao GT 15 e Quadro 2, refere-se ao GT 18:

1. Quadro de categorização de temas encontrados no GT 15

\begin{tabular}{|c|c|}
\hline $\mathbf{N}^{\mathbf{0}}$ & TEMA \\
\hline 1 & Educação Inclusiva $^{1}$ e Políticas Educacionais \\
\hline 2 & Deficiência Auditiva $^{-}$ \\
\hline 3 & Deficiência Visual \\
\hline 4 & Deficiência Intelectual \\
\hline 5 & Deficiência Motora \\
\hline 6 & Transtornos Globais do Desenvolvimento \\
\hline 8 & Altas Habilidades/Superdotação \\
\hline 9 & Educação Inclusiva e Formação de Professores \\
\hline
\end{tabular}

\footnotetext{
${ }^{1}$ Optamos pela utilização do termo Educação Inclusiva, pois muitos dos trabalhos trazem reflexões sobre a prática
} inclusiva com estudantes com deficiência em instituições regulares e raramente em instituições especiais. 


\begin{tabular}{|c|c|}
\hline 10 & Educação Inclusiva e Currículo \\
\hline 11 & Educação Inclusiva e Sala de Recursos Multifuncionais \\
\hline 12 & Educação Inclusiva e Ensino Superior \\
\hline 13 & Educação Inclusiva e Gestão Escolar \\
\hline 14 & Educação Inclusiva e Estado de Arte \\
\hline 15 & Educação Inclusiva e Sexualidade \\
\hline 16 & Educação Inclusiva e Educação Infantil \\
\hline 17 & Educação Inclusiva e Intervenções \\
\hline 18 & Educação Inclusiva e Família \\
\hline 19 & Educação Inclusiva e História \\
\hline 20 & Outros \\
\hline
\end{tabular}

Fonte: Elaborado pelas autoras a partir do banco de dados da ANPEd

2. Quadro de categorização de temas encontrados GT 18

\begin{tabular}{|c|c|}
\hline $\mathbf{N}^{\mathbf{}}$ & TEMA \\
\hline 1 & EJA e Políticas Educacionais \\
\hline 2 & Proeja \\
\hline 3 & EJA e Formação de Professores \\
\hline 4 & EJA e Práticas Pedagógicas \\
\hline 5 & EJA e Currículo \\
\hline 6 & EJA e Educação do Campo/Movimentos Sociais \\
\hline 7 & Sujeitos da EJA \\
\hline 8 & EJA e Gestão Escolar \\
\hline 9 & EJA e Estado de Arte \\
\hline 10 & EJA e Educação Profissional \\
\hline 11 & EJA e Alfabetização e Letramento \\
\hline 12 & EJA e História \\
\hline 13 & EJA e Educação Popular \\
\hline 14 & EJA e Terceira Idade \\
\hline 15 & EJA e Projovem \\
\hline 16 & Juvenilização da EJA \\
\hline 17 & EJA e Contexto de Privação de Liberdade \\
\hline 18 & EJA e Ensino Superior \\
\hline 19 & Outros \\
\hline
\end{tabular}

Fonte: Elaborado pelas autoras a partir do banco de dados da ANPEd

Destacamos que esses temas foram sinalizados por sua grande recorrência nos trabalhos publicados dentro dos GTs 15 e 18 da ANPEd, ou por sua importância dentro do quadro geral de discussões.

Então, classificamos e separamos as publicações de acordo com os temas centrais dos quadros acima. Em seguida, verificamos o total de trabalhos publicados sobre cada tema, e, por fim, após tabulação de dados, elaboramos gráficos que nos auxiliaram a visualizar a quantidade dessas publicações, os quais serão apresentados na terceira seção deste trabalho. 


\subsubsection{Etapa específica}

A etapa específica foi marcada pela exploração do material e referencia o objetivo principal dessa investigação: verificar e analisar o quantitativo e o que revelam as pesquisas que dialogavam com os eixos temáticos de Educação Inclusiva e EJA.

Nesse sentido, após verificarmos quais eram os artigos que traziam a dialogicidade os agrupamos em um quadro comparativo a fim de observamos e fazermos uma comparação das informações iniciais como autoria, título, local, ano e tipo de publicação. Como resultado segue abaixo o quadro 3 com os trabalhos encontrados.

Quadro 3: Quadro de organização dos trabalhos encontrados nos GTs 15 e 18

\begin{tabular}{|c|c|c|c|}
\hline AUTORIA & TİTULO & $\begin{array}{l}\text { LOCAL E ANO DE } \\
\text { PUBLICAÇÃO }\end{array}$ & $\begin{array}{l}\text { TIPO DE PU- } \\
\text { BLICAÇÃO }\end{array}$ \\
\hline $\begin{array}{l}\text { Maria da } \\
\text { Conceição } \\
\text { Bezerra } \\
\text { Varella }\end{array}$ & $\begin{array}{l}\text { EJA e Educação Espe- } \\
\text { cial: caminhos } \\
\text { que se cruzam }\end{array}$ & $\begin{array}{c}\text { ANPED } 34^{\circ} \text { ANO } 2011 \\
\text { GT } 18 \\
\text { Natal - RN } \\
\text { outubro de } 2011\end{array}$ & Artigo \\
\hline $\begin{array}{l}\text { Fabiana Alva- } \\
\text { renga Rangel }\end{array}$ & $\begin{array}{l}\text { A Totalidade da Defi- } \\
\text { ciência e os Direitos } \\
\text { do Homem Egoísta } \\
\text { em Apropriações da } \\
\text { Inclusão Escolar }\end{array}$ & $\begin{array}{c}\text { ANPED } 34^{\circ} \text { ANO } 2011 \\
\text { GT } 15 \\
\text { Natal - RN } \\
\text { outubro de } 2011\end{array}$ & Artigo \\
\hline $\begin{array}{c}\text { Clarissa Haas } \\
\text { Claudio Roberto } \\
\text { Baptista }\end{array}$ & $\begin{array}{l}\text { A Educação de Jovens } \\
\text { e Adultos e a Educa- } \\
\text { ção Especial: os sujei- } \\
\text { tos e as políticas pú- } \\
\text { blicas em foco }\end{array}$ & $\begin{array}{c}\text { ANPED } 36^{\circ} \text { ANO } 2013 \\
\text { GT } 15 \\
\text { Universidade Federal de } \\
\text { Goiás-UFG / Goiânia- } \\
\text { GO } \\
\text { outubro de } 2013 \\
\end{array}$ & Artigo \\
\hline
\end{tabular}

Fonte: Elaborado pela autora a partir do banco de dados dos anais da ANPEd.

Através dos dados sistematizados no quadro 3, conseguimos encontrar apenas três trabalhos que trouxessem o diálogo objetivado nessa investigação. Outra observação é que no recorte temporal de doze anos, as publicações só ocorreram nos anos de 2011 e 2013, antes e depois desse período não há evidências de pesquisas nas áreas no banco virtual da ANPEd.

Para uma melhor dinâmica na elaboração das reflexões, após essas observações iniciais relatadas, determinamos critérios de análise para adentrar nos artigos de forma mais pontual, tendo em vista os pontos que desejávamos desvendar e para orientar as nossas leituras, as quais foram realizadas em caráter de fichamento. Nesse sentido, os critérios de análises escolhidos foram: objetivo da pesquisa, contextualização, metodologia utilizada, pontos de destaque e pontos de limitações. 
2.3. Terceira fase: tratamento e análise dos dados

A última fase deste trabalho foi o tratamento e a análise dados. Com base em Bardin (2011), realizamos a síntese e seleção dos resultados, as nossas inferências e interpretações, das quais decorreram a escrita desta pesquisa. Nesse sentido, procuramos averiguar e refletir sobre o que os dados estavam nos sinalizando. Assim, após a realização dessa terceira fase, e especialmente da exploração dos três artigos selecionados, iniciamos a última seção deste trabalho, de forma a não perder a objetividade da análise da dialogicidade dos trabalhos encontrado que tratavam da Educação Inclusiva na EJA.

\section{A dialogicidade entre a educação inclusiva e a EJA: o que revelam os dados}

Nessa seção procuramos apresentar as reflexões realizadas mediante as análises de dados. Em um primeiro momento refletiremos os diálogos encontrados nos GTs 15 e 18 baseados na etapa geral, em que por meio de tabulações de dados e gráficos verificamos como tem sido organizado os temas e trabalhos publicados. Em seguida falaremos mais especificamente dos três trabalhos averiguados na etapa especifica que traziam o diálogo específico da Educação Inclusiva na EJA.

Como já sinalizamos anteriormente, mediante a realização etapa geral foi possível elaborar gráficos que nos ajudaram a visualizar e refletir sobre como as publicações nos GTs 15 e 18 têm se organizado. Segue abaixo o gráfico 1 que mostra as publicações por temas do GT 15 .

\section{Gráfico 1 - Trabalhos publicados pela ANPEd no GT 15 (2005-2017)}

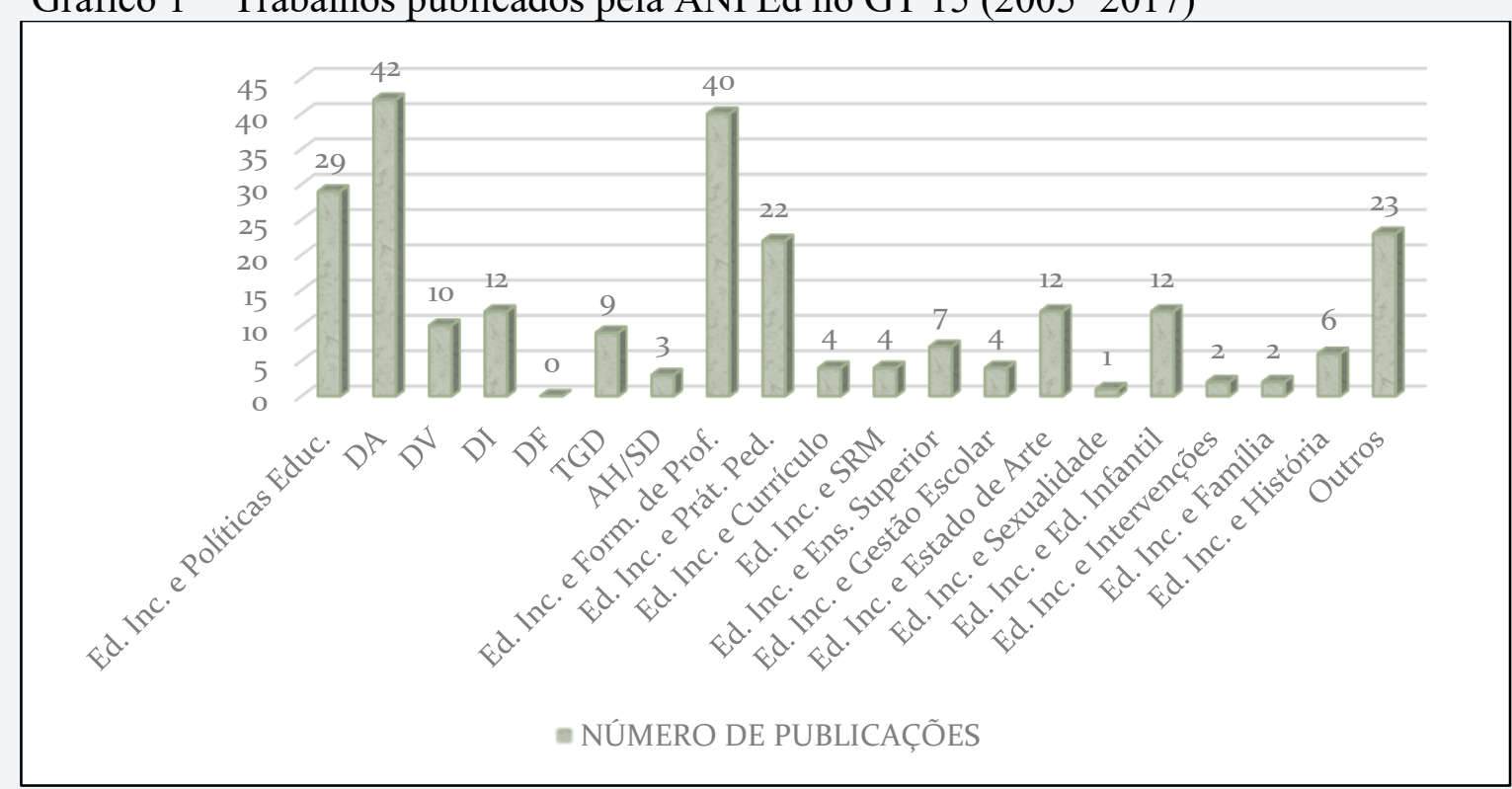

Fonte: Elaborado pelas autoras a partir do banco de dados dos anais da ANPEd. 
Nesse primeiro gráfico, referente ao GT 15, podemos observar que foram contabilizados, entre trabalhos, pôsteres e trabalhos encomendados, 244 artigos. Desse total, os temas com as maiores quantidades de trabalhos publicados foram as discussões sobre Deficiência Auditiva (DA), com 17\% e Educação Inclusiva e Formação de Professores, com 16\%. Estes dados nos permitem problematizar, o "por quê" eles têm sido destaque entre as pesquisas.

Sobre DA, temos as afirmações dos autores Witchs e Lopes (2018), os quais declaram que a comunidade surda tem ganhado muita força e representatividade a cada década. Assim, para que, a cultura surda pudesse se estabelecer tal como a vemos, foi necessário conhecê-la e fazê-la conhecida, por meio de estudos, investigações e principalmente, a exposição desses trabalhos. Os autores esclarecem que o grande fluxo de trabalhos e teorias da compreensão culturalista da surdez, ocorrida segunda metade do século XX, foi considerado uma grande conquista. Nessa época houve igualmente o destaque para "a língua de sinais - artefato primordial que dá sustento à noção dessa cultura - não possuía legitimidade ou reconhecimento linguístico antes da década de 1960". (WITCHS; LOPES, 2018, p. 3)

Já ao que se refere à Educação Inclusiva e Formação de Professores, o autor Saviani (2009), afirma que a falta e a necessidade da formação docente foram preconizadas por Comenius, desde o século XVII. Para ele, apesar do problema de a formação de professores ter se configurado a partir do século XIX, o fenômeno denominado, "formação de professores", surgiu há muitos anos. No que se refere ao diálogo entre os dois temas, o autor apresenta-o como um desafio necessário, pois a questão da formação do professor para atuar na educação especial, ainda permanece em aberta. Para ele, precisamos discutir e pensar a formação do professor para atuar com educação especial de forma mais categórica.

Ainda, o gráfico 1 nos mostra que os temas com o menor número de publicações foram: Deficiência Física (DF) com 0\% de publicações, Educação Inclusiva e Sexualidade com 0,5\%, Altas Habilidade e Superdotação (AH/SD), Educação Inclusiva e Intervenções e Educação Inclusiva e Família representam cada um 1\% das publicações.

No que se refere à tabulação de dados realizados a partir dos materiais coletados no GT 18 da Educação de Jovens e Adultos, temos o gráfico 2 abaixo. 
Gráfico 2 - Trabalhos publicados pela ANPEd no GT 18 (2005-2017)

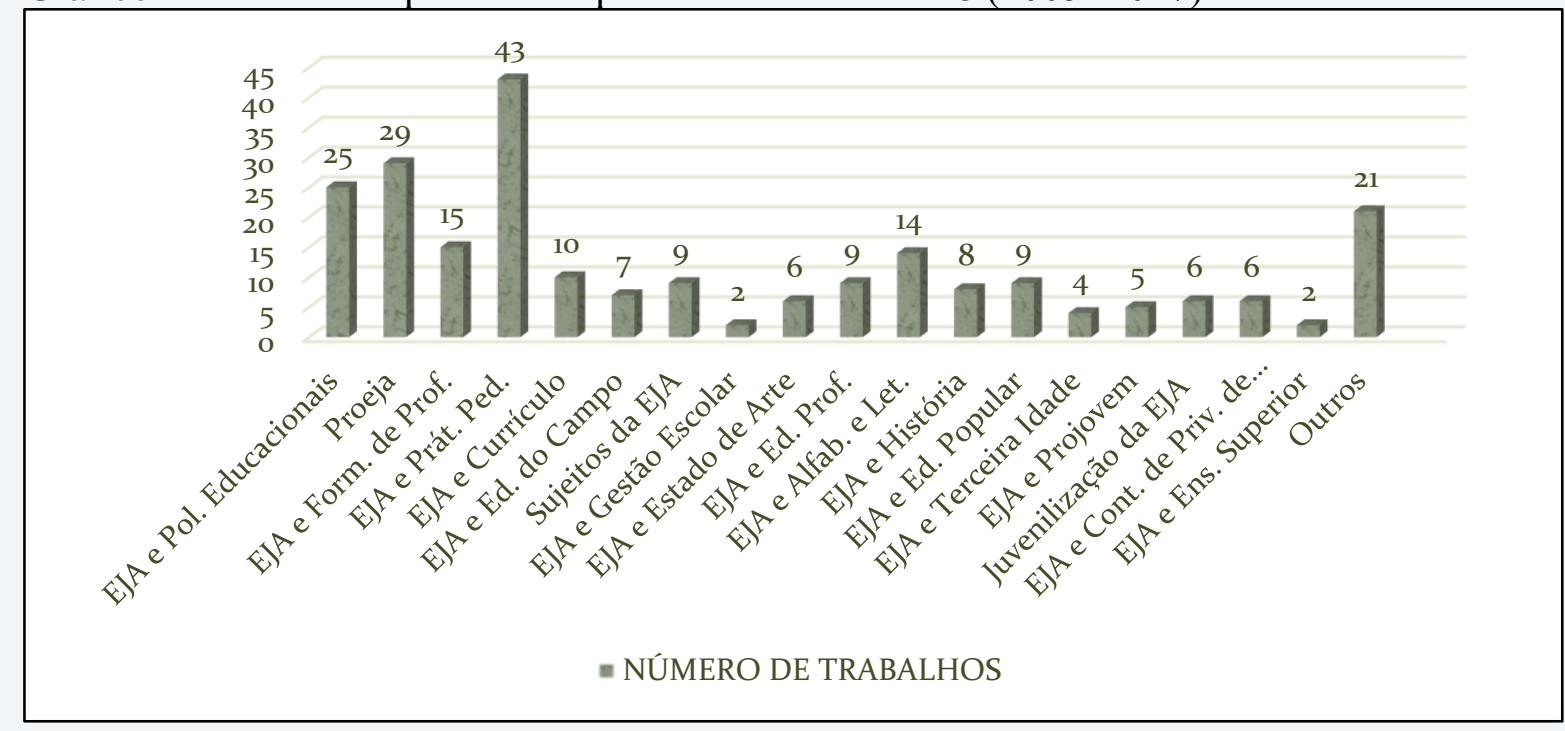

Fonte: Elaborado pelas autoras a partir do banco de dados dos anais da ANPEd.

Como podemos observar no gráfico 2, dentro do GT 18 foram computados 230 artigos. O tema de discussão sobre EJA e Prática Pedagógicas obteve o maior número de publicações, com $19 \%$, seguido pelo tema Proeja, com $13 \%$.

Assim como a modalidade de ensino da Educação Especial, a EJA ainda é percebida como um campo de desafios a serem refletidos e superados. Visto que, como apresenta a autora Moraes (2007), a EJA sucessivamente tem se constituído como um espaço ocupado pelas minorias e segmentos discriminados da sociedade brasileira. Ela afirma que essa modalidade, "trabalha-se como os excluídos, com as 'minorias', com os 'diferentes' e com as 'diferenças'”. (MORAES, 2007, p. 17)

Por isso, as práticas pedagógicas como o tema de maior publicações nos permite deduzir que há uma procurar por entender e até mesmo evidenciar práticas favoráveis ou antagônico dentro da EJA que ajudem a traçar um caminho para o seu melhor desenvolvimento. Isso é algo pertinente, especialmente ao pensarmos na necessidade do fazer pedagógico ser conhecido, praticado e refletido, em favor daqueles que são sujeitos participantes dessa modalidade e a quem ela se destina. Nesse sentido, consideramos muito significativo a expressiva quantidade de trabalhos nessa temática como possibilidade de ampliar horizontes da ação pedagógica e abandonar ou reformular àquelas que já não conseguem satisfazer as necessidades.

Sobre a importância das publicações que reflitam as práticas pedagógicas. Jardilino e Araújo (2014) afirmam que no confronto das suas ações cotidianas com as produções teóricas, há a possibilidade de se rever suas práticas e, inclusive, produzir novos conhecimentos para a teoria e prática de ensinar. Para os autores, à medida que o professor amplia sua consciência 
sobre a própria prática e possui os conhecimentos teóricos e críticos sobre a realidade, a transformação da sua prática docente é efetiva. tanto na de sala de aula, como em toda escola. Assim, eles declaram que essa ação permite aos professores colaborarem "para transformar as escolas em termos de gestão, currículos, organização, projetos educacionais, formas de trabalho pedagógico. (JARDILINO; ARAÚJO, 2014, p. 12)

Ainda, como podemos observar, os temas que traziam a discussão de EJA/Gestão Escolar e EJA/Ensino Superior, representaram apenas $1 \%$ do número da publicação total cada um. Destacamos que trabalhos agrupados como outros nos dois gráficos referem-se a temas que não se enquadravam nas temáticas centrais que forma estabelecidas no processo de análise.

Por fim, nessa etapa geral, analisamos o número de publicações por ano. A fim de verificamos quais anos tiveram mais incidências de artigos publicados e a partir da tabulação dos dados tivemos como resultado os números ilustrados no gráfico 3 abaixo.

Gráfico 3 - Trabalhos publicados por ano na ANPEd dentro dos GTs 15 e 18 (2005-2017)

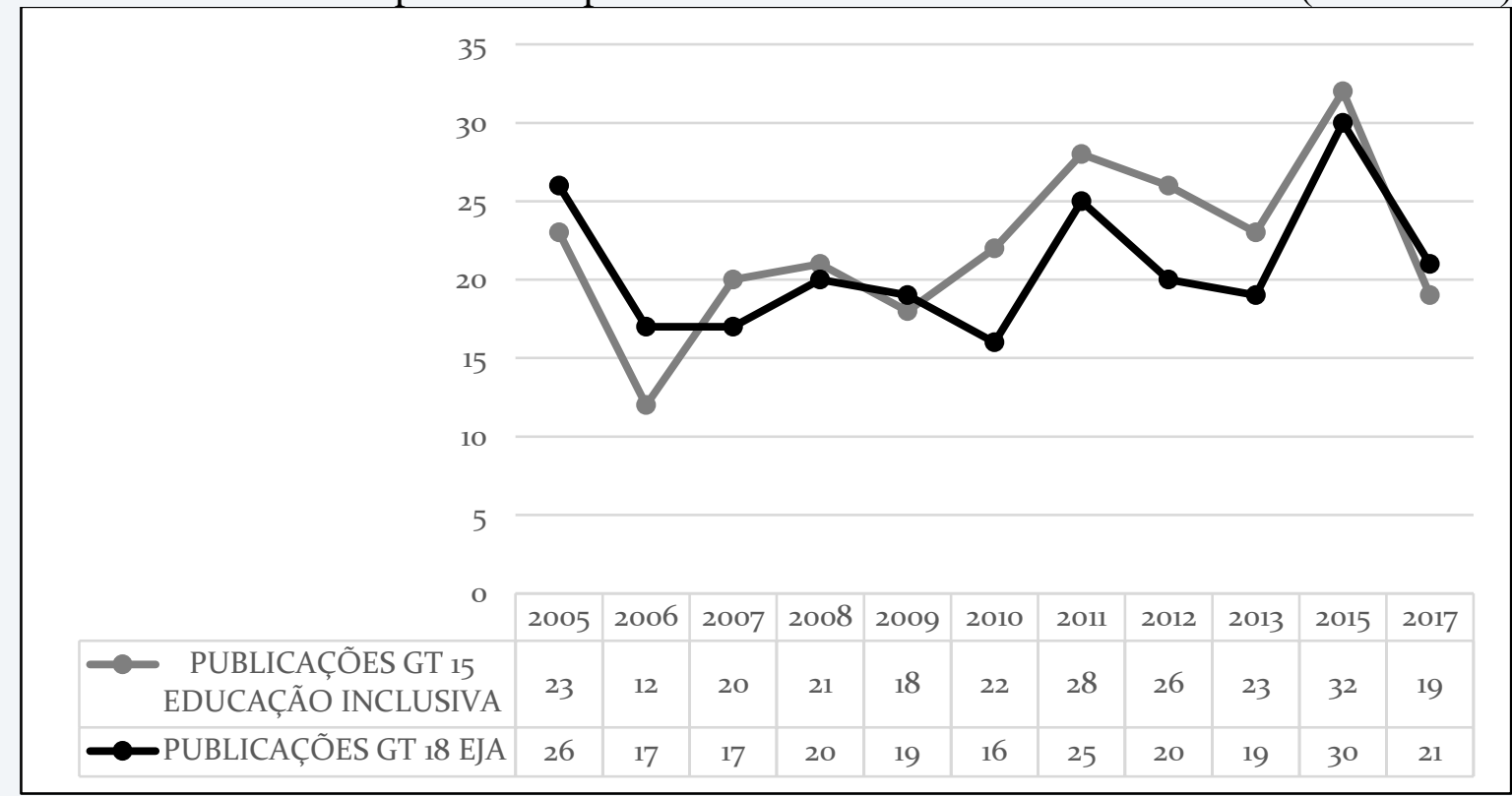

Fonte: Elaborado pelas autoras a partir do banco de dados dos anais da ANPEd.

De acordo com os resultados do gráfico 3 acima, embora os números apontem uma média de 20 a 22 artigos publicado ao ano, não há uma linearidade no quantitativo de dessas publicações. Além disso, observamos que os dois GTs tiveram a maior quantidade no mesmo ano - 2015 - representando $13 \%$ do valor total. Já o menor difere entre os eles, pois o do GT 15 foi o ano de 2012 e do GT 18, ano de 2010. 
Por fim, nessa etapa geral, conseguimos constatar o número total de publicações que trouxessem a dialogicidade dos dois GTs, que será mostrado na figura 2 do diagrama abaixo. Somente após essas contatações e análises, passamos para a etapa específica.

Figura 2: Critérios para catalogação dos dados

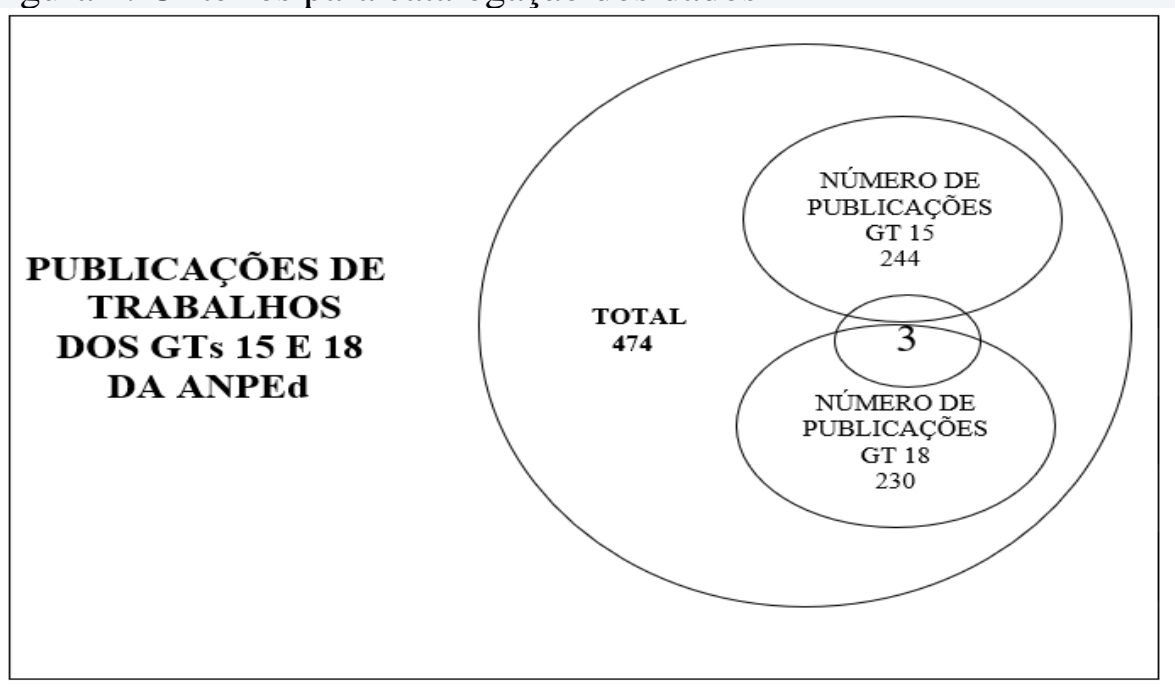

Fonte: Elaborado pelas autoras

Como se pode notar na Figura 2, dos 474 trabalhos encontrados, apenas 4 deles traziam o diálogo entre a Educação Inclusiva e a EJA, que representa 0,85\% publicações. Algo que evidencia e justifica a relevância desse trabalho.

Posto isso, adentramos nesse momento ao que revelam os três artigos encontrados que traziam o diálogo entre as temáticas de Educação Inclusiva e EJA. Assim, por meio dos critérios já citados, das leituras e fichamentos, apresentamos os resultados observados e refletidos.

Entendemos que a educação destinada a jovens e adultos, que por algum motivo não tiveram acesso, ou não deram continuidade aos estudos e retornaram nessa modalidade, é por si só uma forma de inclusão. Na medida que a percebemos como uma possibilidade de incluir aqueles que tiveram, de algum modo, os seus direitos negados. Considerando esses aspectos, vemos a EJA como um espaço de inclusão e não apenas para pessoas jovens e adultas sem escolaridade; mas para sujeitos excluídos, que passaram e passam por diversos tipos de preconceitos, seja por sua etnia, religião, classe social, gênero, condições físicas e psicológicas, deficiências etc.

Segundo Miron e Reis (2017), não é coerente pensar sobre a Educação Inclusiva na EJA, sem a compreensão do que significa inclusão e ao que ela se propõe. Para a autora, a inclusão não se refere apenas incluir alunos com deficiência no âmbito escolar, mas parte do pressuposto que todos nós em algum dado momento de nossas vidas precisaremos de uma educação na 
perspectiva inclusiva, como forma de ajudar a enfrentar dificuldades ou barreiras que impedem a nossa plena formação como ser humano.

Entretanto, partindo das reflexões às quais este trabalho se propõe, a inclusão dos estudantes com deficiência na EJA estaria dissociada a qualquer tipo de preconceito, segregação e discriminação. Além do que, inclusão não pode ser associada à integração, pois, segundo Montoan (2006, p. 17), essas palavras possuem "posicionamentos teórico-metodológicos divergentes".

Miron e Reis (2017), ao fazerem um paralelo entre integração e inclusão, apresentam que a primeira pode possibilitar a inserção do aluno com deficiência de forma parcial no âmbito escolar, uma vez que esse discente não é percebido como sendo realmente parte do meio onde está. E tanto o sistema de ensino, como os serviços educacionais destinados a ele ocorrem, em sua maior parte, de forma segregada. Já a inclusão refere-se a ações que rompem com os paradigmas que mantêm o conservadorismo das escolas, e não apenas percebe o aluno com deficiente com um sujeito participante da educação e aceita suas diferenças individuais, mas oportunizar vivências para o exercício dessa participação, que deve ser integral e em cooperação com os demais participantes da escola.

Sobre essas vivências com os demais, Ferreira (2009) afirma que na escala mundial, a maior parte das pessoas com deficiência não con-vivem ${ }^{2}$ com pessoas sem deficiência. No entanto essa convivência não tem sido verdadeiramente vínculos que permitam a construção de uma relação harmoniosa e duradoura. Algo que representa um problema, pois como a autora destaca, a ausência dessa vivência física real das pessoas com deficiência com pessoa sem deficiência, seja em locais e espaços públicos ou privados, impede o estabelecimento de "laços indispensáveis para qualquer indivíduo se identificar e se tornar parte de um dado grupo". (FERREIRA, 2009, p. 81)

Ainda, a autora mostra que no contexto das profundas desigualdades, o jovem e o adulto analfabeto com deficiência seguem sendo matriculados em escolas ou classes especiais; e quando em turmas regulares do ensino fundamental, com crianças pequenas. Entretanto, o próprio estudo realizado por Ferreira (2009) traz indícios de uma crescente conscientização das secretarias de educação e comunidades escolares "sobre a necessidade de incluir jovens e adultos com deficiência estudar nas turmas de EJA, a fim de propiciar a convivência com seus pares da mesma faixa etária”. (FERREIRA, 2009, p. 77)

\footnotetext{
${ }^{2}$ A autora traz essa expressão por compreender que a convivência com pessoas com deficiência não tem sido verdadeira e real. Trata-se de uma vivência superficial e de tolerância, mas sem estímulos para a criação de laços e empatia.
} 
Por isso, compreender que refletir a dialogicidade entre a Educação Inclusiva e a EJA, por meio de trabalhos publicados, torna-se relevante a partir da necessidade de verificar o que as pesquisas e estudos têm revelado, que pontos podem ser aprofundados e até mesmo que outras reflexões podem ser feitas entre esse diálogo.

Partindo disso, o primeiro artigo analisado foi "EJA e Educação Especial: caminhos que se cruzam", da autora Maria da Conceição Bezerra Varella (2011). O objetivo do trabalho apresentado foi a discussão das interfaces da EJA e Educação Especial. O artigo utilizou como metodologia a pesquisa bibliográfica e a análise documental, sendo desenvolvido por meio de análise documentos legais e políticas públicas, as quais são base e validam a Educação especial na perspectiva da Educação Inclusiva e a EJA, tanto em Natal-RN, lugar de análise da autora, como em todo o país.

Já ao que se refere aos pontos de destaques da produção, que promovem a dialogicidade das duas modalidades, estão na maneira da autora traçar um caminho envolvente em suas reflexões sobre a presença de oscilação e fragilidade nas políticas inclusivas voltas ao aluno com deficiência à EJA. Segundo ela, infelizmente, no município de Natal-RN, não há uma articulação entre as políticas inclusivas da Educação Especial com a EJA. E faltam informações e dados precisos em sistemas que organizam as modalidades. Varella (2011) também destaca que isso não acontece apenas no município investigado, mas é a nível nacional. Outro ponto de destaque é a necessidade formação específica para professores que atuam na EJA, pois as práticas pedagógicas inclusivas não apresentam eficácia na aprendizagem, tanto de pessoas com deficiência ou sem, dentro da modalidade. Ainda, destacamos sua análise sobre a transversalidade da Educação Especial em todos os níveis da Educação.

Posto isso, os pontos de limitações observados referem-se a aspectos mais pontuais, que podem levar o leitor, em um primeiro momento, a confundir os desdobramentos dados ao trabalho. Isso porque, no período inicial em que foi realizada a leitura do resumo e a introdução do artigo, parecia que o objeto de estudo destacado pela autora seria usado como um paralelo de discussão entre realidade vivenciada pela aluna com paralisia cerebral na EJA e as discussões dos documentos e políticas analisados. Segue abaixo um trecho que nos levou a essa interpretação,

Reflete-se aqui sob o foco de um caso de uma adolescente com paralisia cerebral, com graves sequelas motoras numa turma de EJA nível III. Ela se propôs percorrer as trilhas da inclusão escolar, levando a comunidade escolar a descobertas que perpassam o desvelamento de posturas, concepções e novos conhecimentos, assim como outras tantas adolescentes nas mesmas condições por este país. (VARELLA, 2011, p. 1) 
Todavia, compreendemos no decorrer do desenvolvimento do trabalho que o objeto foi a inspiração para a proposição de analisar e refletir sobre o que os documentos e políticas inclusivas traziam em relação aos alunos com deficiência na EJA.

O segundo artigo analisado foi o "A Totalidade da Deficiência e os Direitos do Homem Egoísta em Apropriações da Inclusão Escolar”, da autora Fabiana Alvarenga Rangel (2011). O objetivo deste trabalho foi refletir alguns efeitos e tramas provocados pelo discurso da Inclusão Escolar não apenas no espaço da escola, mas de maneira a focar nos sujeitos que transitam por ela e que a fazem escola.

O percurso metodológico do artigo analisado é marcado pela investigação de duas escolas públicas de um município da região metropolitana do Espírito Santo. Para tanto, Rangel (2011) informa que a escolha dessas escolas ocorreu por uma atender um jovem de vinte e quatros anos que apresenta deficiência mental e laudo de esquizofrenia. E a outra, ser frequentada por uma jovem de vinte anos de idade, apresentando espinha bífida e fazendo uso de cadeira de rodas. A autora apresenta que fragmentos das falas utilizadas foram obtidas por meio de questionários e entrevistas. Sendo que os questionários foram respondidos por auxiliares de serviços gerais, pedagogas, professores e uma coordenadora de turno. Já as entrevistas foram semiestruturadas e realizadas com uma pedagoga e uma professora.

Os pontos de destaques da produção podem ser sinalizados pela forma como Rangel (2011) traz o diálogo das reflexões em torno do processo de inclusão por meio de um olhar filosófico de Emmanuel Lévinas. De modo a problematizar, ao tempo que traz ideias centrais sobre a totalidade do ser, o Outro, o Mesmo, o sujeito egoísta, ao longo do trabalho. Além disso, procura sinalizar o erro de ver a pessoa com deficiência somente pela deficiência e não olhar como um ser humano em sua totalidade. Através das análises de dados, percorre um caminho que mostra que o espaço da escola é onde está instaurada uma concepção de inclusão equivocada, fundamentada, muitas vezes, apenas nas adaptações dos espaços físicos. No que se refere às limitações, ao iniciarmos a leitura, por meio das exposições feitas pela autora, vemos que ela se propõe a mostrar e a dialogar sobre dois casos, mas ao final dos trabalhos percebemos uma exposição maior e reflexões apenas de um.

Por fim, o último artigo que analisamos foi "A Educação de Jovens e Adultos e a Educação Especial: os sujeitos e as políticas públicas em foco", produzido pelos autores Clarissa Haas e Claudio Roberto Baptista. Como expostos por Haas e Baptista (2013), o objetivo do trabalho foi analisar as trajetórias escolares de sujeitos jovens e adultos com deficiência a partir de narrativas e das conexões com os fenômenos educacionais que definem as alternativas de 
escolarização para eles. No que se refere ao percurso metodológico, os autores utilizaram metodologia de história oral, com enfoque em uma de suas divisões: a história oral de vida; a qual permite a utilização da marca da subjetividade como lugar de pertença à produção de um pensamento científico. Assim, por meio de três sujeitos centrais, procuram trazer suas trajetórias de vidas, para compreender as teias que amarram, aproximam e distanciam a dialogicidade entre as áreas da Educação Especial e da EJA.

Sobre os pontos de destaques desse trabalho, verificamos o uso da metodologia de história oral para chegar às reflexões apresentadas, pois por meio dos relatos dos sujeitos entrevistados, o leitor tem um envolvimento maior com os sentimentos impressos nas falas. Ainda, a forma como denuncia o fato de que as instituições de Educação Especial não têm cumprido os seus objetivos de se estabelecerem como um período transitório para os sujeitos que a buscam e de reintegrálos no Ensino Comum. Segundo os autores,

As práticas escolares vivenciadas no espaço da Escola Especial, por Lucas e Sonia, sinalizam a ausência de um currículo escolar que avance além do compromisso da escola com a alfabetização desses sujeitos. Fica evidente, nas singularidades propostas pelas histórias aqui destacadas, que o ensino exclusivamente especializado tem cumprido um papel de estagnação e permanência, dificultando os laços com a escola e com a sociedade. A frequente justificativa desses espaços como transitórios, nestes casos, não se confirma. (HAAS; BAPTISTA, 2015, p. 15)

Os autores, ao fazerem a dialogicidade entre Educação Especial e EJA, mostram esses contrapontos. E acentuam o fato de que esta última tem sido um espaço que precisa de grandes melhorias, mas que proporcionou na vida dos investigados transformações significativas. Uma vez que por meio dela os sujeitos investigados desenvolverem critérios de análise relativos às experiências vividas nos dois ensinos: especializado e comum, pois assumem uma posição bastante crítica em relação às práticas escolares nos dois espaços. As limitações baseiam-se no fato do leitor ficar com dúvidas no que se refere ao percurso metodológico, que não dá conta de fazer-nos entender como ocorreu a escolha dos participantes da pesquisa e onde foram entrevistados.

\section{Considerações finais}

A partir de todos os dados apresentados, constatamos que as pesquisas que relacionam a Educação Inclusiva dentro da EJA ainda são um quantitativo muito pequeno. Dos 474 trabalhos publicados dos GTs investigados, apenas três se reportavam à temática. 
Ainda, conseguimos constatar, por meio das análises feitas, que dentre esses trabalhos encontrados, um traz a dialogicidade nas reflexões bibliográficas e análise documental. Porém, os outros dois apresentam o diálogo entre Educação Inclusiva e EJA por meio de investigações feitas no campo da escola, dando voz aos sujeitos participantes da modalidade. No entanto, apesar dessas diferenciações, não dizemos que um trabalho sobressaia ao outro, pois como verificamos, os três procuram, mediante as suas colocações e reflexões, trazer importantes contribuições para a compreensão da ação inclusiva dentro da EJA.

Ao apresentar os documentos legais, Varella (2011) nos fez refletir que estamos amparados legalmente para trilharmos uma educação inclusiva, não apenas para jovens e adultos, mas para todos. Todavia, muitos são os sinais que evidenciam o distanciamento entre o que está na lei e a prática educativa efetiva. Isso porque falta a execução de ações afirmativas que promovam a inclusão de todos na educação e que de fato coloquem em vigor o cumprimento da lei. No caso da EJA temos por exemplo, a Lei de Diretrizes e Base da Educação (LDB), no Art. 4, inciso VII, que afirma, "oferta de educação escolar regular para jovens e adultos, com características e modalidades adequadas às suas necessidades e disponibilidades [...] condições de acesso e permanência na escola". (BRASIL, 2019, p. 2, grifo nosso). Como vemos, a própria lei traz que as especificidades são pontos cruciais que devem ser levados em conta, a fim de possibilitarem que haja o acesso e a permanência, e nós ainda pontuamos o sucesso desse estudante. Nesse sentido, o trabalho de Varella (2011) nos ajuda a pensar sobre esses aspectos.

Já os trabalhos que foram desenvolvidos no campo da escola por Rangel (2011) e Haas e Baptista (2013) faz-nos compreender a necessidade de escutarmos os sujeitos que estão e são participantes da educação e que vivenciam ou não ações de inclusão. A autora Rangel (2011), por exemplo, em uma perspectiva inovadora traz o olhar do filosofo Emmanuel Lévinas principalmente para apresentar que a pessoa com deficiência é um ser total e como tal deve ser valorizado e compreendido como um ser humano. Algo que vai contra o estabelecimento de paradigmas, estereótipos de normalidade e todo tipo de "pré-conceito".

Os autores Haas e Baptista (2013) trazem em suas apresentações e diálogo pontos instigantes e provocadores que nos induzem a refletir no potencial emancipatório proporcionado pela EJA aos sujeitos jovens e adultos com deficiência. Assim, eles pontuam, mediante aos relatos dos próprios discentes, que esses estudantes quando frequentavam apenas a educação especial, não se viam como pessoas ativas e que tivessem a possibilidade de ir além das suas limitações. Mas ao entrarem na EJA tiveram a oportunidade de conviver com pares diferentes e passaram a estabelecer vontades próprias, opiniões e reflexões sobre suas trajetórias. 
Claro que não queremos apresentar a EJA como a solução de problemas, mas por meio de todos esses diálogos realizados dentro desses trabalhos, podemos constatar que é possível pensar em uma educação para jovens e adultos em uma perspectiva da inclusão. Além disso, verificamos a importância das pesquisas que podem servir de base e inspirações para outras investigações. Destacamos também que os autores mostram clareza em suas exposições e permitem que o/a leitor/a compreenda a importância dos trabalhos.

Por fim, evidenciamos que apesar da relevância dos artigos analisados, ainda há muitas lacunas dentro da reflexão dessa temática. Temos como exemplo, questões relacionadas à formação dos professores da EJA que atuam com alunos com deficiência dentro da perspectiva inclusiva; de que como a perspectiva está sendo formulada dentro da modalidade EJA; a relação dos pares da EJA tendo como base a educação na perspectiva inclusiva; o currículo na perspectiva da inclusão em favor do aluno com deficiência na EJA, entre outras.

Assim, entendemos que grandes são os desafios e possibilidades de mais trabalhos, estudos e pesquisas dentro temática investigada como um modo de proporcionar reflexões essenciais para a melhoria e mudanças na educação, não apenas de alunos com deficiência na EJA, mas como a todos os envolvidos na Educação.

\section{REFERÊNCIAS}

BARDIN, Laurence. Análise de conteúdo. São Paulo: Edições 70, 2011.

BRASIL. Lei de Diretrizes e Bases da Educação Nacional n 9.394, de 20 de dezembro de 1996. Brasília, 2019.

HAAS, Clarissa; BAPTISTA, Claudio Roberto. A Educação de Jovens e Adultos e a Educação Especial: os sujeitos e as políticas públicas em foco. In: $36^{\mathrm{a}}$ Reunião Nacional da ANPEd, 37. 2013, Goiás, Anais [...]. UFG: Goiás. Disponível em: http://36reuniao.an-

ped.org.br/pdfs_trabalhos_aprovados/gt15_trabalhos_pdfs/gt15_3032_texto.pdf. Acesso em: 25 mar. 2020.

JARDILINO, José Rubens de Lima; ARAÚJO, Regina Magna Bonifácio de. Educação de Jovens e Adultos: sujeitos saberes e práticas. São Paulo: Cortez, 2014.

MIRON, Keren Talita Silva; REIS, Sônia Maria Alves de Oliveira. A inclusão de alunos com necessidades educacionais especiais na Educação de Jovens e Adultos: algumas discussões.

Revista Práxis Educacional, Vitória da Conquista, v. 13, n. 24, p. 95-116, jan./abr. 2017. Disponível em: http://periodicos2.uesb.br/index.php/praxis/article/view/932. Acesso em: 20 mar. 2020.

MORAES, Salete Campos de. A EJA como espaço de inclusão e empoderamento. In: MORAES, Salete Campos de. Educação Especial na EJA: contemplando a diversidade. Porto Alegre, Prefeitura Municipal de Educação, 2007, p. 13-22. 
MOROSINI, Marília Costa; FERNANDES, Cleoni Maria Barboza. Estado do Conhecimento: conceitos, finalidades e interlocuções. Educação Por Escrito, Porto Alegre, v. 5, n. 2, p. 154164, jul.-dez. 2014. Disponível em: http://revistaseletronicas.pucrs.br/ojs/index.php/porescrito/article/view/18875. Acesso em: 18 mar. 2020.

MOROSINI, Marilia Costa. Estado de conhecimento e questões do campo científico. Revista Educação. Santa Maria, v. 40, n. 1, p. 101-116, jan./abr. 2015. Disponível em: https://periodicos.ufsm.br/reveducacao/article/view/15822. Acesso em: 25 jan. 2020.

RANGEL, Fabiana Alvarenga. A totalidade da deficiência e os direitos do homem egoísta em apropriações da inclusão escolar. In: 34ª Reunião Nacional da ANPEd, 34., 2011, Natal.

Anais [...]. Natal. Disponível em: http://34reuniao.anped.org.br/images/trabalhos/GT15/GT15-341\%20int.pdf. Acesso em: 21 mar. 2020.

RIZOLA, Jairo; FANTIN, Nádia. Revisão da Literatura e Revisão Sistemática da Literatura. RELVA, Juara/MT/Brasil, v. 3, n. 2, p. 23-39, jul./dez. 2016. Disponível em: https://periodicos.unemat.br/index.php/relva/article/view/1738. Acesso em: 25 jan. 2020.

SAVIANI, Dermeval. Formação de professores: aspectos históricos e teóricos do problema no contexto brasileiro. Rev. Bras. Educ., abr. 2009, vol.14, n. 40, p. 143-155. Disponível em: http://www.scielo.br/pdf/rbedu/v14n40/v14n40a12.pdf. Acesso em: 10 fev. 2020.

VARELLA, Maria da Conceição Bezerra. EJA e Educação Especial: caminhos que se cru-

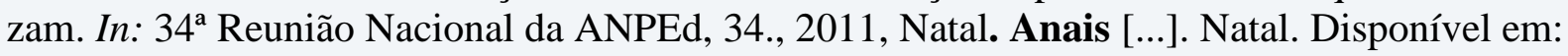
http://34reuniao.anped.org.br/images/trabalhos/GT18/GT18-831\%20int.pdf. Acesso em: 21 de jul. 2019.

WITCHS, Pedro Henrique; LOPES, Maura Corcini. Forma de vida surda e seus marcadores culturais. Educ. Rev. [online]. 2018, vol. 34, ago. 2018. Disponível em: http://www.scielo.br/pdf/edur/v34/1982-6621-edur-34-e184713.pdf. Acesso em: 21 jan. 2020.

\section{SOBRE AS AUTORAS:}

\section{Keren Talita Silva Miron}

Mestranda em Educação no Instituto Federal Catarinense (IFC) Campus Camboriú. Graduada em Pedagogia na Universidade do Estado da Bahia, Campus XII. Grupo de pesquisa: Linguagem, Cognição e Tecnologia. E-mail: keren_talita@hotmail.com

(iD http://orcid.org/0000-0002-1270-2603

\section{Chris Royes Schardosim}

Doutora em Linguística pela Universidade Federal de Santa Catarina (UFSC). Professora do Instituto Federal Catarinense (IFC), atuando no Programa de Pós-Graduação em Educação do IFC. Grupo de pesquisa: Linguagem, Cognição e Tecnologia. E-mail: chris.schardosim@ifc.edu.br.

(iD http://orcid.org/0000-0002-2303-2377 